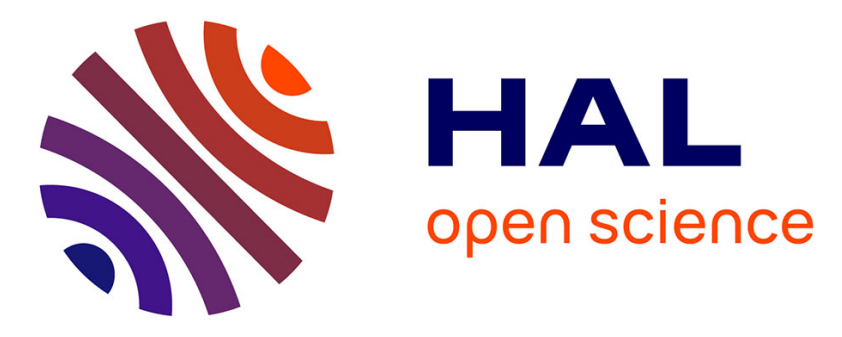

\title{
When the Giant meets the Ant An Asymmetric Approach for Collaborative Object Manipulation
}

Morgan Le Chénéchal, Jérémy Lacoche, Jérôme Royan, Thierry Duval, Valérie Gouranton, Bruno Arnaldi

\section{- To cite this version:}

Morgan Le Chénéchal, Jérémy Lacoche, Jérôme Royan, Thierry Duval, Valérie Gouranton, et al.. When the Giant meets the Ant An Asymmetric Approach for Collaborative Object Manipulation. 3DUI 2016: 11th IEEE Symposium on 3D User Interfaces, Mar 2016, Greenville, SC, United States. IEEE, pp.273 - 274, 2016, 10.1109/3DUI.2016.7460078 . hal-01301770

\section{HAL Id: hal-01301770 https://hal.science/hal-01301770}

Submitted on 12 Apr 2016

HAL is a multi-disciplinary open access archive for the deposit and dissemination of scientific research documents, whether they are published or not. The documents may come from teaching and research institutions in France or abroad, or from public or private research centers.
L'archive ouverte pluridisciplinaire HAL, est destinée au dépôt et à la diffusion de documents scientifiques de niveau recherche, publiés ou non, émanant des établissements d'enseignement et de recherche français ou étrangers, des laboratoires publics ou privés. 


\section{When the Giant meets the Ant An Asymmetric Approach for Collaborative Object Manipulation}

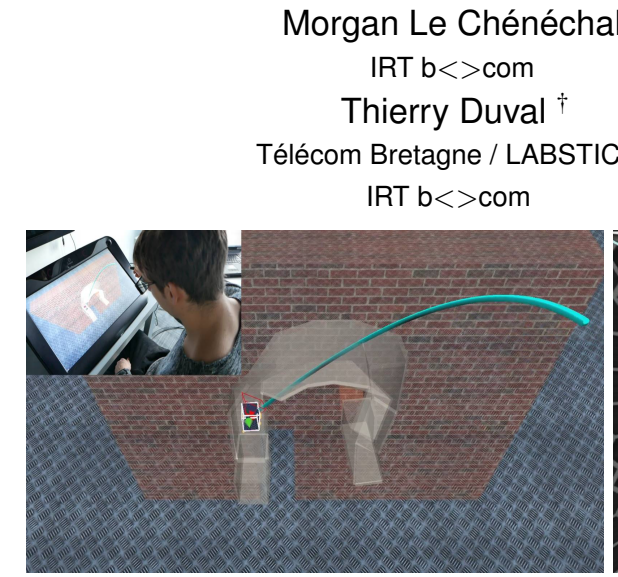

(a)

\author{
Jérémy Lacoche * \\ IRT $\mathrm{b}<>$ com \\ Valérie Gouranton * \\ INSA Rennes / Irisa/INRIA \\ IRT $\mathrm{b}<>$ com
}

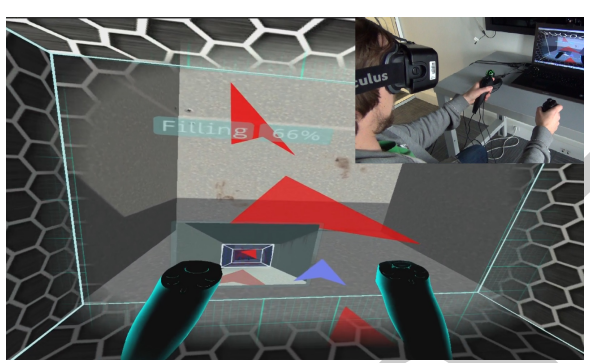

(b)

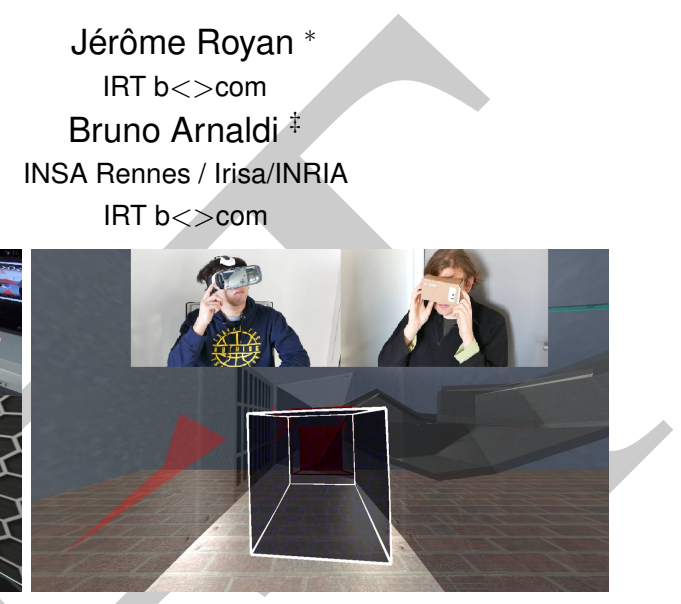

(c)

Figure 1: Collaborative manipulation of a virtual cube based on an asymmetric setting between two users who can be helped by two additional users. (a) The first participant has a global view of the scene and moves the cube with a 3D bent ray. (b) The second user is placed inside the cube and precisely rotates and scales it. (c) Two additional roles can be added. The first one helps to scale the cube using a third person view of the cube. The other one is a spectator who switches between the other participants' viewpoints and helps them with oral communication.

\section{ABSTRACT}

For the 3DUI Contest 2016, we propose an innovative approach that enables two or more users to manipulate an object collaboratively. Our solution is based on an asymmetric collaboration pattern at different scales in which users benefit from suited points of views and interaction techniques according to their device setups. Our system provides an efficient way to co-manipulate an object within irregular and narrow courses, such as the contest material scenes, taking advantages of asymmetric roles in synchronous collaboration.

Keywords: Collaborative 3D Interactions ; Shared Virtual Environments

Index Terms: H.5.3 [nformation interfaces and presentation (e.g HCI)]: Group and Organization Interfaces-Computer supported cooperative work (CSCW); I.3.6 [Computer Graphics]: Methodology and Techniques-Interaction techniques

\section{INTRODUCTION}

This work proposes a set of metaphors that enables several users to collaborate in order to achieve common manipulation tasks in Virtual Reality (VR). For instance, the tasks proposed for the contest consist in overcoming different obstacles by moving, rotating and scaling a cube collaboratively. In order to cover the different requirements of the 3DUI contest, we propose an asymmetric collaboration between 2 or more users with different devices (cf. Fig. 1). The users are embedded in a co-located multi-scale virtual environment thanks to a model inspired from the Immersive Interactive Virtual Cabin (IIVC) generic model [2]. We chose to use devices that are or will be soon on the consumer market. Our solution is designed to be easy to use and to learn and aims improving a difficult manipulation task using collaboration.

\footnotetext{
*e-mail:\{morgan.lechenechal,jeremy.lacoche,jerome.royan\}@b-com.com

$\dagger$ e-mail: thierry.duval@telecom-bretagne.eu

†e-mail: \{valerie.gouranton,bruno.arnaldi\} @ irisa.fr
}

\section{Asymmetric COLLABORATIVE SCENARIO}

We propose an asymmetric collaboration where each user benefits from interaction capabilities adapted to his interaction devices.

Global View: the Giant The first user is interacting on a $\mathrm{zS}$ pace as shown in Figure 1a. It is composed of a 3D stereoscopic display with head tracking and of a 3D tracked stylus for interacting. This user has a global view of the scene and can roughly manipulate the cube in order to move it really fast in easy passages.

Micro View: the Ant The second user visualizes the scene with a Head-Mounted Display (HMD), here an Oculus Rift as shown in Figure 1b. He is interacting with a Razer Hydra composed of two 3D tracked controllers. This user is placed inside the cube and can manipulate it with a fine accuracy. His role is essential to overcome difficult passages.

Third Helping User As shown in Figure 1c, the third user is interacting with a GearVR, an HMD with a 2D trackpad. His role is optional. He has a third person view of the manipulated cube. He is able to help the Ant to scale it with slide gestures on the trackpad.

Spectators The last role is a spectator. It is available on multiple devices. In our scenario, he uses a Google Cardboard as shown in Figure 1c. Multiple spectators can be included in the shared virtual environment. These users can switch between the other participants' viewpoints. Here, it is done by pulling the Cardboard trigger. They can help the other participants by giving oral instructions.

\section{Interaction Techniques}

The collaborators benefit from complementary interaction techniques to perform the manipulations tasks proposed for the contest.

\subsection{Global Manipulation}

The user on the zSpace (Giant) can translate the cube with a bent ray inspired from the interaction technique proposed by Riege et al. [6]. The ray is controlled in position and rotation by the tracked stylus. One button is used for object grabbing, and the other buttons are used to switch between four point of views: front, left, back and right. The ray is bent during the cube translation in order to respect three constraints: 


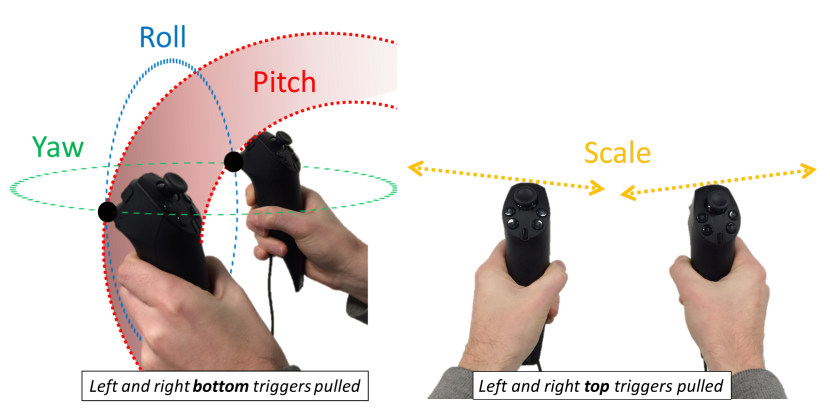

Figure 2: The two metaphors used by the Ant to rotate and scale the manipulated object.

- First, the manipulated cube is attached to the ray extremity with a spring joint, as proposed by Fröhlich et al. [3]. The physical collider of the cube avoids it to pass through other objects. The ray is bent accordingly.

- Second, we manually limit the ray extremity speed when an object is grabbed. The goal is to not disturb the distant user inside the manipulated cube and reduce his cybersickness.

- Third, a last constraint is optional. We added an active help for the translation. It is a magnetic path that represents the perfect path to follow. The manipulated object is also connected to the closest point on this path with a spring joint.

To make the others understand the Giant's actions, his head, stylus and 3D ray are rendered in the shared environment as shown on the top of Figure 3.

\subsection{Inside Object Manipulation}

The Ant is placed inside the manipulated object, here a cube. He can scale and rotate it with the two Razer Hydra controllers thanks to bimanual metaphors inspired from the work of Cutler et al. [1]. These manipulations are performed with a fix reference: the cube front face. This reference face can be changed with a button. These manipulations are physically constrained, the manipulated object can not pass through an obstacle. As shown in Figure 2, the rotation is made with a modified version of the grab-and-twirl metaphor. Compared to the classical version, the pitch rotation is performed with a metaphor close to a plane yoke by orienting the two controllers to the top or to the bottom. The scale of the cube is controlled with a grab-and-scale metaphor by bringing closer or further the two Razer Hydra controllers while pushing two corresponding buttons. The scale control is shared with the user of the GearVR. To solve this concurrency, we add the factors that the two users want to apply to the scale. Two visual feedbacks are rendered to make the Ant understand the distance between the cube and possible obstacles. First, we render particles at the collision points. Second, a virtual grid visible in blue at bottom in Figure 1b, parallel to the user current front face, is displayed outside of the cube.

To guide the Ant when he is placed in a closed environment such as the provided labyrinth, different spatial cues can help him. They are shown in Figure 1b. First, a World-In-Miniature [7] shows a third person view the that focuses on the cube. Second, an arrow simulates a compass to show him the direction to follow. Third, in the labyrinth, the path to follow is also indicated with arrow signs.

As shown in Figure 1b, a progressive transparency effect is applied to the manipulated cube from the screen extremities to the screen center (cf. [5]). Here, it is used as an anti-cybersickness filter that aims to make the peripheral view of the user consistent with his head movement. Therefore, the user's peripheral view is less disturbed by translations performed by the Giant. Some preliminary evaluations of this effect have been performed in another context and have shown good results.

For awareness issues, the viewpoint of the Ant is shown to the other users by displaying his frustum and up vector.

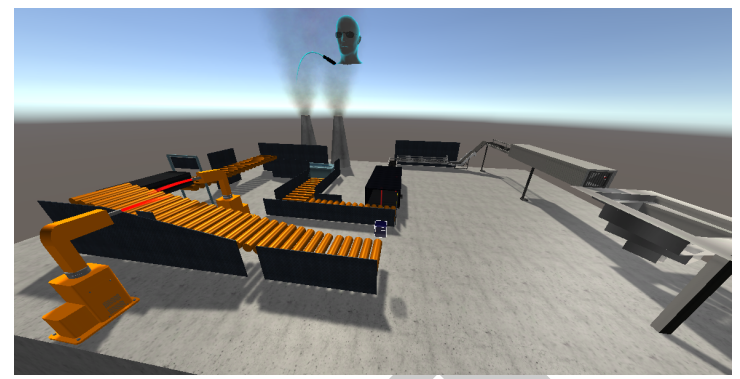

Figure 3: An additional scene to assess the advantages of our approach: a virtual factory in which the Ant can trigger different actions such as opening doors or painting the cube.

\section{IMPLEMENTATION}

Regarding the implementation of the prototype, a software overlay of SmartFox Server is used to manage collaboration. For the rendering, scripting and managing the scene we use the Unity3D game engine. The interaction part is independent from the devices and from the game engine used. Indeed, it is developed with an implementation of the plasticity models presented by Lacoche et al. [4]. With this solution, each user automatically benefits from the adapted interaction techniques according to his available devices. We have used the different scenes provided for the contest. Some textures have been added to stylize the demonstrator as shown in Figure 1a for the labyrinth. Another scene is also available in order to demonstrate other advantages of our interaction metaphors. It is the virtual factory, shown in Figure 3, where the Ant can perform different actions such as painting the box or opening doors.

\section{Perspectives}

Preliminary users tests show a good efficiency of the different interactions techniques. A formal evaluation should be done in order to compare our proposal with a solution from the state-of the art where the collaboration is symmetric. Moreover, in our current proposal, only the scale of the cube can be concurrently modified by several users. We plan to add a concurrent access to its rotation by providing this capability to the Giant. In particularly difficult passages, the bending of the Giant's ray will dynamically define his power in the concurrent cube rotation in order to take the lead on the Ant.

\section{REFERENCES}

[1] L. D. Cutler, B. Fröhlich, and P. Hanrahan. Two-handed direct manipulation on the responsive workbench. In Proceedings of the 1997 symposium on Interactive 3D graphics, page 107114, 1997.

[2] C. Fleury, A. Chauffaut, T. Duval, V. Gouranton, and B. Arnaldi. A Generic Model for Embedding Users' Physical Workspaces into MultiScale Collaborative Virtual Environments. In ICAT 2010, Adelaide, Australia, Dec. 2010.

[3] B. Fröhlich, H. Tramberend, A. Beers, M. Agrawala, and D. Baraff. Physically-based manipulation on the responsive workbench. In $V R$, 2000. Proceedings. IEEE, pages 5-11. IEEE, 2000.

[4] J. Lacoche, T. Duval, B. Arnaldi, E. Maisel, and J. Royan. Plasticity for 3D User Interfaces: new Models for Devices and Interaction Techniques. In EICS 2015. ACM.

[5] J. Lacoche, M. Le Chénéchal, S. Chalmé, J. Royan, T. Duval, V. Gouranton, É. Maisel, and B. Arnaldi. Dealing with frame cancellation for stereoscopic displays in 3d user interfaces. In 3DUI 2015, pages 73-80. IEEE, 2015.

[6] K. Riege, T. Holtkamper, G. Wesche, and B. Fröhlich. The bent pick ray: An extended pointing technique for multi-user interaction. In 3DUI 2006, pages 62-65, March.

[7] R. Stoakley, M. J. Conway, and R. Pausch. Virtual reality on a WIM: interactive worlds in miniature. In Proceedings of the SIGCHI conference on Human factors in computing systems, page 265272. ACM Press/Addison-Wesley Publishing Co., 1995. 